\title{
Western European markets for biosimilar and generic drugs: worth differentiating
}

\author{
Livio Garattini $^{1} \cdot$ Alessandro Curto $^{1} \cdot{\text { Katelijne van de } \text { Vooren }^{1}}^{1}$
}

Published online: 20 March 2015

(c) Springer-Verlag Berlin Heidelberg 2015

\section{Introduction}

Health is a typical field where the economic theory of market competition does not enjoy the basic conditions to work. The pharmaceutical market, in which the most important private health care industry flourishes, is no exception; rather, it is one of the most striking examples of market failure (on both the demand and supply sides) caused by lack of price competition. To tackle these problems, public intervention on pricing and reimbursement has traditionally been far more extensive than on most other goods.

Research and development (R\&D) activity characterizes the pharmaceutical industry, and the flow of new drugs is protected by patents to remunerate investments. As soon as a patent expires, competition is opened up and any manufacturer can copy the originator product; in principle, this should push industry to reinvest its profits in R\&D and constrain any "economic rent" too.

This circumstance justifies the place in the pharmaceutical market for generics and biosimilars, i.e. off-patent medicines that can be sold at lower prices than their originators, with no loss of quality, safety and efficacy to patients.

While generics have been widely used throughout the world for decades, this is not yet the case for the more recent biosimilars, of which only six have been approved by the European Medicines Agency (EMA) so far [1]:

Livio Garattini

lgarattini@marionegri.it

1 CESAV, Center for Health Economics, IRCCS Institute for Pharmacological Research 'Mario Negri', Via Camozzi 3, 24020 Ranica, Italy epoetin, filgrastim, somatropin, follitropin alfa, infliximab and insulin glargine (Table 1).

Here we compare these two types of off-patent medicines using the well-known business tool of "4P's (product, place, promotion, and price) marketing mix" [2], which proved suitable for casting light on their differences, looking particularly at what makes biosimilars special, beyond the way they are produced. We mainly refer to Western European countries since generics have been in use there for decades alongside in-patent drugs.

\section{Product}

A generic medicine is a chemical drug designed and developed to be equivalent to its originator (the 'reference medicine'), which has already been authorized. It should contain the same active ingredient(s) as the reference medicine and be used at the same dose(s) to treat the same disease(s). Only the inactive ingredients (the 'excipients') can differ in the generic and its originator [3]. The concept of bioequivalence is fundamental for generics. These small, not very complicated, chemical entities are fairly easy to synthesize and their performance in humans is, of course, predictable because they are exact copies of the originators. European guidelines limit the requirement for clinical studies to certain circumstances, to reduce unnecessary and costly clinical trials (CTs) as far as possible [4].

A biosimilar product is designed and developed to be similar to an original biological medicine whose patent has expired. A biosimilar and its originator contain essentially the same active biological substance, though there may be minor differences due to their complex nature and production methods [5]. Like the reference medicine, the biosimilar can have some natural variability from one batch 
Table 1 Biosimilars approved by EMA up to December 2014 [1]

\begin{tabular}{ll}
\hline Active substance & Brand name \\
\hline Epoetin alfa & Abseamed \\
& Binocrit \\
Epoetin zeta & Epoetin Alfa Hexal \\
Filgrastim & Retacrit \\
& Silapo \\
& Accofil \\
& Biograstim \\
& Filgrastim Hexal \\
& Grastofil \\
Follitropin alfa & Nivestim \\
Infliximab & Ratiograstim \\
Insulin glargine & Tevagrastim \\
Somatropin & Zarzio \\
\hline & Bemfola \\
& Ovaleap \\
& Inflectra \\
& Remsima \\
& Abasria \\
& Omnitrope \\
& \\
&
\end{tabular}

to another, batch-to-batch variability (microheterogeneity) being a feature of any biological agent. Consequently, even changes in the biological originators' manufacturing processes aimed at increasing production efficiency require extensive analyses of pre- and post-change products (comparability exercise), with subsequent approval by regulatory authorities. While this is generally mentioned to cast doubts on the equivalence of biosimilars and reference products, it may be at the same time used to claim their superiority because of their up-to-date production methods [6]. However, according to EMA [5] neither an 'inferior' nor a 'superior' product should be approved as a biosimilar, on account of the potential for differences in biological activity and/or safety. Stringent criteria are required in studies for biosimilars' approval that compare their quality, safety and effectiveness with the originator, to show the clinical irrelevance of their variability and differences, if any [5]. Therefore, a biosimilar needs an extensive head-tohead comparison with the originator to confirm the resemblance between its physicochemical and biologic characteristics, safety, and efficacy and those of its 'parent'. In practice, the type and amount of clinical data required for each biosimilar can vary a lot, depending on (1) the complexity of the active substance and how thoroughly it can be characterized, (2) the availability of an accepted surrogate end-point for comparing efficacy, (3) the type and seriousness of safety concerns already reported for the reference product, and (4) the possibility of extrapolating efficacy and safety data to other indications for the reference product that have not been researched for the biosimilar. In theory, if the same mechanism of action of the active substance and the target receptor(s) are involved in the tested and extrapolated indication(s), extrapolation should not pose any problem [7].

\section{Place}

Most generics and the few biosimilars so far approved are prescribed in quite different settings. Although varying according to the type (e.g. "Beveridgean" in the UK and Italy or "Bismarckian" in Germany and France [8]) and framework of health care systems, the former are mainly prescribed in primary care by general practitioners (GPs), who are self-employed independent practitioners in most Western EU countries, the latter are used more by specialists, particularly by hospital doctors, who are employees in all countries but the Netherlands [9]. This means their distribution channels can differ too. Generics are mainly dispensed through community pharmacies in all countries, while biosimilars (which are mainly injectables) are usually first used in hospital, so the influential role of community pharmacists is still limited overall.

These different settings of the two kinds of products substantially affect their promotion and pricing.

\section{Promotion}

Many policies have been in place to promote the use of generics for decades in many Western EU countries. An important question for generics worldwide in the long run is how patients perceive the safety and quality of the products, and this is mainly influenced by health professionals. Although it is easy to demonstrate bio-equivalence, pharmaceutical companies sometimes have an obvious interest in discrediting generics and undermining their credibility among prescribers [10], who in turn are reluctant to prescribe them widely if they have no financial incentive from health authorities to compensate their loss of influence. Only a few European countries have introduced a direct "stick-and-carrot" budgetary approach aimed at boosting the prescription of cheaper drugs among GPs (e.g. GP fundholding in the UK and pharmaceutical expenditure targets in Germany) [11].

Broadly, community pharmacists are keener about generics, their interest mainly reflecting whether commercial incentives offered by the generics' manufacturers more than offset their lower margins (than the originators) and the extra time needed to inform patients. Although in many countries (e.g. France, Germany and Italy) distribution margins (as a proportion of public prices) apparently 
penalise generics if their regressive effect is not heavy enough, the marketing strategies by generics' manufacturers (mainly extra rebates and payment delays) soften their impact in practice [11].

In general, the traditional international non-proprietary name (INN) prescription in countries like the UK (differently from France, Italy and Spain) has certainly favoured the diffusion of generics, overriding the controversial attitudes of GPs and community pharmacists [12].

Biosimilars have not really caught on yet. They still face substantial barriers when competing with branded originators for market share and third-party payers seem cautious about encouraging their spread, probably because they are still not sure how exactly to interpret the concept of similarity and fear risks of immunogenicity. As far as we know, France is the only country that has allowed automatic substitution for biosimilars, although under certain conditions: (1) naïve patients only, (2) without the prescriber's prohibition, and (3) limited to products included in a "similar biologic" group drawn up by the national agency for approval (Agence Nationale de Sécurité du Médicament et des produits de santé, ANSM), although details on this issue are still lacking [13]. In Germany the National Association of Statutory Health Insurance Funds (GKV) has agreed with the National Association of Statutory Health Insurance Physicians (Kassenärztliche Bundesvereinigung) on a quota for biosimilars (more than half the total volume) in the group of epoetins, to stimulate their uptake [14].

Extrapolation to other indications for the biosimilar may be another big hurdle when the originator has several indications (examples are epoetin and infliximab) and the similarity has been confirmed in CTs only for one of the indications at approval. The 'similar but not identical' principle and the traditional use of CTs to assess a drug's efficacy and safety may arouse suspicion among the medical professionals involved in their prescription, even though extrapolation has to be based on rigorous characterization and comparison of structural and functional characteristics using advanced modern analytical tools [7] so that repetition of the entire development programme of the reference product would be scientifically unnecessary and a potential waste of money [15]. Besides, extrapolation of data has been accepted for many years even when the manufacturing process of originators has undergone major changes [7]. Finally, because biologicals are often injected subcutaneously (e.g. somatropin and insulin glargine), delivery devices closely linked to a specific product can become a further hurdle undermining an easy switch to biosimilars [16].

In general, however, the fact that medical consultants and hospital pharmacists in Western EU countries are mostly employees should make it simpler for health authorities to introduce budgetary tools that boost the promotion of biosimilars.

\section{Price}

Of course, investing in copies is much less risky than in innovative drugs requiring more expensive $R \& D$ activity. As discussed above, approval for marketing a generic normally requires only limited investments for investigating clinical safety and efficacy. Prices can therefore sometimes be as low as half those of the originators and often even $80 \%$ less [17], potentially leading to considerable savings for health authorities if prescribers do not switch to in-patent "me-too" drugs [18-20].

Most national authorities have specific pricing and reimbursement schemes for generics, to encourage their wider use and limit pharmaceutical expenditure [11]. The most common price regulation system in the Western EU countries is the so-called reference pricing (RP) scheme, under which health authorities set a maximum price for products containing the same active ingredient so patients have to cover any cost of equivalent products exceeding the RP [21]. Introduced in Germany (Festbeträge) in 1989 for the first time and 2 years later in the Netherlands, an RPlike scheme has now been adopted in France, Italy and Spain, the last Western EU countries where generics were launched, because of national patent extension laws approved before European harmonization [11]. Germany and the Netherlands [18] have now shifted to tendering in community care too, allowing their health insurers to restrict reimbursement to the cheapest product(s) only. RP may raise concern among the general population on the real equivalence of drugs in the long term, The underlying and emerging message that cheaper generics are like "hard discount" low-quality products in mass markets compared with originators and so patients should be willing to pay more for "brand" products is simply false since generic drugs have to be equivalent to originators.

As an average, prices of biosimilars are only discounted 20-30 \% compared with the originators so far [22]. Companies maintain that this relatively small price difference reflects the substantial investment needed to develop and market a biosimilar. The time to develop a biosimilar is estimated at 7-8 years, at a cost of \$100-\$250 million (a 100 -fold increase the $\$ 1-\$ 4$ million estimated for a generic) [23].

Pricing arrangements for biosimilars in the Western EU countries are still confused and uneven. Countries like Germany and the Netherlands have included the first biosimilars approved (epoetin and filgrastim) under RP, like generics, while in Italy [24] and Spain [25, 26] many regional authorities purchase biosimilars through tenders. 


\section{Discussion}

Biosimilars can be considered "new" off-patent medicines made by a biological process. Only a few are on the European markets right now, but the number of top-selling biologics about to come off-patent in the next 5 years (e.g. adalimumab, cetuximab, etanercept, rituximab and trastuzumab) is fuelling considerable interest [27].

Biosimilars and generics have different characteristics: the latter, with their small, simple chemical structures, are considered identical to their reference medicines. However, the complexity of the biological/biotechnology-derived products makes the standard generic approval procedure based on bioequivalence not applicable for the former, so a specific comprehensive strategy for comparisons is called for, including CTs [28]. The complicated biological production process, even though it greatly influences the characteristics of the end-product, is kept a company secret. Therefore, biosimilar manufacturers have to design the production site at their own discretion, implying that CTs are mandatory for comparing products since laboratory tests alone are not specific enough. Disclosure of the production process could lead to easier and more exact copying of the originator, preventing costly and ethically questionable CTs on biosimilars [7]. We wonder whether international agencies like EMA could not oblige companies to disclose this information for biologics before patent expiry, a practice which is not necessarily inconsistent with patent protection in our view. In general, more health authorities should hinder the widespread habit of big pharmaceutical companies of introducing in-patent pharmaceutical forms just before patent expiries (see subcutaneous injection of trastuzumab as a very recent example [29]). Although this kind of 'life-cycle' strategy to re-launch mature products is legal, we feel it is more like 'malpractice' allowed by the present patent regulation to undermine price competition, extending protection by deliberately delayed launches.

Since, as we pointed out before, hospitals and health authorities employ most medical specialists, it should be simpler for them to promote biosimilars. Not having to deal with GPs' and community pharmacists' attitudes towards generics, health authorities could exploit straightforward managerial tools-like their budgets- to boost the prescription of biosimilars.

The often mentioned concern about the quality of generics should not pose any great problem for biosimilars. Not only are there only a few manufacturers-who can be easily inspected-but most of them are well-established pharmaceutical companies. The two examples of recently approved biosimilars may be emblematic. Although marketed under two different brands, infliximab is manufactured by only one company, so it is just one product in practice. Moreover, the manufacturer has been contracted for production [30] and contacted for acquisition [31] by big multinational companies of biological originators.

Insulin glargine will have only one biosimilar, although co-promoted by two multinational companies specialized in diabetes care. Since one of them is the manufacturer, it will be hard for the originator's company to argue about the biosimilar's quality. Besides, the EMA's annual periodic safety update reports for these drugs have not yet identified any differences between biosimilars and reference products in frequency, type, or severity of adverse events [22]. To our knowledge, the only accident for biologics so far involved batches of the epoetin originator [32].

Biosimilars, like generics before them, will find it hard to carve out a niche in the pharmaceutical arsenal without offering health authorities considerable savings. Though manufacturers claim that price cuts should be much smaller on biosimilars than on generics, there are doubts about this. Biosimilars incur higher development costs than generics partly because CTs are required for approval and partly because manufacturing them is more complicated. While CT costs could be lowered simply by adapting patent regulations (as discussed above), fixed costs like production hardly account for a large proportion of the ex-factory prices of in-patent drugs [33]. This seems even less probable for the sky-high priced monoclonal antibodies whose patents are due to expire soon.

Tenders might offer the most effective way of lowering the prices of biosimilars. However, to achieve real savings the bids must be designed to encourage effective competition, at least allowing more than one manufacturer to compete for the same lot [34]. For instance, while the average price of somatropin has remained stable in Italy in recent years, that of filgrastim decreased more than $50 \%$ thanks to competitive regional tendering.

\section{Policy implications}

Before taking appropriate decisions, national authorities always need to become familiar with new trends emerging in industry and must appreciate the intrinsic economic limits of the pharmaceutical market, i.e. the lack of competition. However, right now international patent regulation seems to be the main hurdle to the spread of biosimilars. Revealing production details well in advance of a patent's expiry would help biosimilars contribute more to sustainable pharmaceutical expenditure, which is particularly important in this period of unprecedented economic crisis, when all possible means to constrain health care budgets without a negative impact on health should be explored. Here we put forward a very general proposal open to debate. 
Once this major international barrier has been overcome and biosimilars reconnected to generics from a regulatory point of view, the widespread diffusion of biosimilars on domestic markets at competitive prices will be managed more or less successfully by national authorities, as has happened for generics for decades.

\section{References}

1. EMA. European Public Assessment Reports. Biosimilars. http:// www.ema.europa.eu/ema/index.jsp?curl=pages\%2Fmedicines $\%$ 2Flanding\%2Fepar_search.jsp\&mid=WC0b01 ac058001d124\& searchTab=searchByAuthType\&alreadyLoaded=true\&isNewQu ery $=$ true $\&$ status $=$ Authorised $\&$ status $=W i t h d r a w n \&$ status $=$ Suspen ded\&status=Refused\&keyword=Enter+keywords\&searchType= name \&taxonomyPath $=\&$ treeNumber $=\&$ searchGeneric Type=bio similars\&genericsKeywordSearch=Submit. Accessed 15 Jan 2015

2. McCarthy, J.E.: Basic marketing. A managerial approach. Irwin RD, Homewood (1964)

3. EMA/393905/2006 Rev 2. Questions and answers on generic medicines. http://www.ema.europa.eu/docs/en_GB/document library/Medicine_QA/2009/11/WC500012382.pdf (2012). Accessed 9 Dec 2014

4. EMA. CPMP/EWP/QWP/1401/98 Rev. 1/Corr **. Guideline on the investigation of bioequivalence. London. http://www.ema. europa.eu/docs/en_GB/document_library/Scientific_guideline/ 2010/01/WC500070039.pdf (2010). Accessed 9 Dec 2014

5. EMA/837805/2011. Questions and answers on biosimilar medicines (similar biological medicinal products). http://www. ema.europa.eu/docs/en_GB/document_library/Medicine_QA/2009/ 12/WC500020062.pdf (2012). Accessed 9 Dec 2014

6. Dörner, T., Strand, V., Castañeda-Hernández, G., et al.: The role of biosimilars in the treatment of rheumatic diseases. Ann. Rheum. Dis. 72(3), 322-328 (2013)

7. Weise, M., Kurki, P., Wolff-Holz, E., Bielsky, M.C., Schneider, C.K.: Biosimilars: the science of extrapolation. Blood 124(22), 3191-3196 (2014)

8. van der Zee, J., Kroneman, M.W.: Bismarck or Beveridge: a beauty contest between dinosaurs. BMC Health Serv Res 7, 94 (2007)

9. Schäfer, W., Kroneman, M., Boerma, W., et al.: The Netherlands: health system review. Health Syst. Transit. 12(1), v-xxvii, 1-228 (2010)

10. Hassali, M.A., Wong, Z.Y., Alrasheedy, A.A., Saleem, F., Mohamad Yahaya, A.H., Aljadhey, H.: Perspectives of physicians practicing in low and middle income countries towards generic medicines: a narrative review. Health Policy 117(3), 297-310 (2014)

11. Garattini, L., Tediosi, F.: A comparative analysis of generics markets in five European countries. Health Policy 51(3), 149-162 (2000)

12. Miguel, L.S., Augustin, U., Busse, R., et al.: Recognition of pharmaceutical prescriptions across the European Union: a comparison of five Member States' policies and practices. Health Policy 116(2-3), 206-213 (2014)

13. Taylor L. France moving ahead with biosimilar substitution. http://www.pharmatimes.com/Article/14-04-13/France_moving _ ahead_with_biosimilar_substitution.aspx (2014). Accessed 9 Dec 2014

14. GKV-Spitzenverband. Rahmenvorgaben nach § 84 Abs. 7 SGB V-Arzneimittel-für das Jahr 2015 vom 26 September 2014. http://www.gkv-spitzenverband.de/suche/suche?default=true\&qu ery $=$ biosimilar $\& x=0 \& y=0$. Accessed 9 Dec 2014
15. Weise, M., Bielsky, M.C., De Smet, K., et al.: Biosimilars: what clinicians should know. Blood 120(26), 5111-5117 (2012)

16. Farfan-Portet, M.I., Gerkens, S., Lepage-Nefkens, I., et al.: Are biosimilars the next tool to guarantee cost-containment for pharmaceutical expenditures? Eur J Health Econ 15, 223-228 (2014)

17. Godman, B., Shrank, W., Wettermark, B., et al.: Use of generics-a critical cost containment measure for all healthcare professionals in Europe? Pharmaceuticals 3(8), 2470-2494 (2010)

18. Dylst, P., Vulto, A., Simoens, S.: Tendering for outpatient prescription pharmaceuticals: what can be learned from current practices in Europe? Health Policy 101(2), 146-152 (2011)

19. European Commission. Pharmaceuticals: sector inquiry and follow up. Final report, factsheet 1: prices, time to generic entry and consumer savings. http://ec.europa.eu/competition/sectors/phar maceuticals/inquiry/index.html (2009). Accessed 9 Dec 2014

20. Woerkom, M.V., Piepenbrink, H., Godman, B., et al.: Ongoing measures to enhance the efficiency of prescribing of proton pump inhibitors and statins in the Netherlands: influence and future implications. J. Comp. Eff. Res. 1(6), 527-538 (2012)

21. Giuliani, G., Selke, G., Garattini, L.: The German experience in reference pricing. Health Policy 44(1), 73-85 (1998)

22. Bennett, C.L., Chen, B., Hermanson, T., et al.: Regulatory and clinical considerations for biosimilar oncology drugs. Lancet Oncol 15(13), e594-e605 (2014)

23. Blackstone, E.A., Joseph, P.F.: The economics of biosimilars. Am Health Drug Benefits 6(8), 469-478 (2013)

24. Curto, A., van de Vooren, K., Lo Muto, R., Duranti, S., Garattini, L.: Regional tenders on biosimilars in Italy, potentially competitive? GaBI J 2(3), 123-129 (2013)

25. Sahuquillo MR. El Gobierno lanza la primera compra centralizada de fármacos. El Pais 27 December 2011. http://sociedad. elpais.com/sociedad/2012/12/27/actualidad/1356641122_491730. html. Accessed 9 Dec 2014

26. Ortega E. Medicamentos biológicos de marca y biosimilares competirán en los mismos concursos públicos. Redacción Médica 25 November 2014. http://www.redaccionmedica.com/secciones/ industria/biologicos-de-marca-y-biosimilares-competiran-en-losmismos-concursos-publicos-5934. Accessed 9 Dec 2014

27. GaBI Journal. US $\$ 67$ billion worth of biosimilar patents expiring before 2020. http://www.gabionline.net/Biosimilars/General/US67-billion-worth-of-biosimilar-patents-expiring-before-2020 (2014). Accessed 9 Dec 2014

28. EMA CHMP/437/04. Guideline on similar biological medicinal products. http://www.ema.europa.eu/docs/en_GB/document library/Scientific_guideline/2009/09/WC500003517.pdf (2005). Accessed 9 Dec 2014

29. van de Vooren, K., Curto, A., Garattini, L.: Cost-effectiveness of trastuzumab in metastatic breast cancer: mainly a matter of price in the EU? Health Policy 119(2), 212-216 (2015)

30. PR Newswire. Celltrion signs manufacturing agreement with Bristol-Myers Squibb Company. http://www.prnewswire.co.uk/ news-releases/celltrion-signs-manufacturing-agreement-with-bris tol-myers-squibb-company-153811165.html (2014). Accessed 9 Dec 2014

31. Reuters. S.Korea's Celltrion shares jump on reports of bid interests from Roche, Teva. http://www.reuters.com/article/2014/ 01/08/celltrion-sale-idUSL3N0KI0MD20140108 (2014). Accessed 9 Dec 2014

32. Brinks, V., Hawe, A., Basmeleh, A.H., et al.: Quality of original and biosimilar epoetin products. Pharm. Res. 28(2), 386-393 (2011)

33. DiMasi, J.A., Hansen, R.W., Grabowski, H.G.: The price of innovation: new estimates of drug development costs. J Health Econ 22(2), 151-185 (2003)

34. Curto, S., Ghislandi, S., van de Vooren, K., Duranti, S., Garattini, L.: Regional tenders on biosimilars in Italy: an empirical analysis of awarded prices. Health Policy 116(2-3), 182-187 (2014) 